\title{
Mejora genética en el cultivo del tabaco. Mecanismos moleculares y regulación
}

\author{
Genetic improvement in tobacco crops. Molecular \\ mechanisms and regulation
}

\author{
(iD) Eduardo Menéndez Álvarez ${ }^{\natural}$, (iD) Julio Navarro Falconípy (iD Fernando Ochoa Paredes² \\ ${ }^{1}$ Universidad Le Cordon Bleu. Lima, Perú \\ 2Universidad Nacional de Cañete. Lima, Perú
}

\begin{tabular}{llll}
\hline Recibido: 15/10/2019 & Revisado: 15/12/2020 & Aceptado: 21/01/2020 & Publicado: 18/06/2020 \\
\hline
\end{tabular}

\section{RESUMEN}

Las enfermedades producidas por hongos fitopatógenos son una de las principales causas de pérdidas de las cosechas desde que el hombre comenzó a cultivar plantas. Hasta el presente, estas enfermedades han sido controladas fundamentalmente mediante: el mejoramiento de la resistencia de las plantas a través de programas de selección y cruzamiento, el empleo de productos agroquímicos y la adecuada rotación de los cultivos. Sin embargo, estas estrategias no son suficientes para el control de las enfermedades causadas por hongos porque los largos períodos de tiempo necesarios para realizar los cruzamientos y retro-cruzamientos así como la selección de variedades comerciales, son suficientes para que aparezcan nuevas razas de hongos con diferentes niveles de virulencia; por otro lado, el uso de productos agroquímicos resulta costoso y eventualmente pierden eficiencia con la evolución del patógeno, además de ser potencialmente peligrosos para el ecosistema. Aplicando las modernas técnicas de la biotecnología vegetal, así como la ingeniería genética, es posible obtener plantas que se autoprotejan contra los hongos o los grupos de hongos en un corto tiempo. Se estudia el caso tabaco, como modelo para entender los mecanismos moleculares de transferencia y regulación que podrán ser aplicados en cultivos de alta importancia económica como la papa.

Palabras clave: Bacterias patógenas, cultivos, Agrobacterium tumefaciens, genes VIR, resistencia.

\begin{abstract}
Diseases produced by phytopathogenic fungi are one of the main causes of crop loss since humans started growing plants. Until now, these diseases have been mainly controlled by the improvement of plant resistance by means of selection and crossbreeding programs, the use of agrochemical products and an accurate crop rotation. Nevertheless, these strategies are not enough to control diseases caused by fungi because of the necessary long periods of time to carry out the crossbreeding and backcrossing as well as the selection of commercial varieties, which is plenty of time for new fungi types with different levels of virulence to appear. On the other hand, the use of agrochemical products is expensive and these eventually lack efficacy as a result of the evolution of the pathogen,
\end{abstract}


apart from being extremely dangerous to the ecosystem. Implementing modern techniques of plant biotechnology as well as genetic engineering makes possible the obtainment of plants that protect themselves against fungi or fungal groups in short time. Tobacco is studied as a model to understand the molecular mechanisms of transference and regulation, which could be applied to crops of high economic importance such as the potato.

Keywords: Pathogenic bacteria, crops, Agrobacterium tumefaciens, VIR genes, resistance.

\section{INTRODUCCIÓN}

El tabaco (Nicotiana tabacum L.) es una de las más de 7000 especies que componen la familia Solanaceae (Clarkson et al., 2004). Esta especie es un anfidiploide de 48 cromosomas que no se ha reportado en estado silvestre. Betancourt (1991) y Siva et al., (2008), coincidieron en que la especie surgió como un híbrido natural que posiblemente tenga como progenitores a Nicotiana silvestris L. y a Nicotiana tomentosiformis L. Este cruzamiento debió ocurrir en los actuales andes peruanos- ecuatorianos- bolivianos, región única donde han sido localizados ambos progenitores y es el centro original de su cultivo (Vavilov, 1936; Burns, 1982).

El cultivo del tabaco tiene una gran importancia económica y amplia explotación mundial, llegó a ocupar el séptimo lugar de las plantas cultivadas en el mundo después del trigo, arroz, maíz, soya, algodón y café, sin embargo, hoy en día no está entre las 15 más cultivadas, esto en gran medida por las campañas para disminuir los hábitos de fumar, que si bien han incidido en la disminución del consumo desde el año 2000, los valores logrados no son suficientes para alcanzar los objetivos acordados para el año 2025 por la Organización Mundial de Salud (OMS). El cultivo del tabaco, se practica en cerca de 100 países in- cluyendo mayoritariamente a países en vías de desarrollo, donde se destacan: China (mayor productor y consumidor) India y Brasil (OMS, 2019).

\section{Patógenos}

El cultivo del tabaco en el mundo es atacado por numerosas plagas y organismos fitopatógenos, que causan daños y enfermedades (tabla 1) que en diferentes grados afectan al cultivo.

Cualquiera de estos organismos puede, de una forma u otra, causar daños severos en las zonas tabacaleras. Las afectaciones en el cultivo se reducen o pueden ser controladas con tratamientos preventivos y la aplicación de los programas de mejoramiento, que han estado dirigidos fundamentalmente a la introducción en las variedades comerciales, de los genes relacionados con la resistencia contra estos patógenos y a la obtención de nuevas variedades, que tengan algún nivel de resistencia a algunos de estos patógenos. Algunos de estos patógenos son considerados como muy peligrosos para las plantaciones, destacándose, en orden de importancia: Peronospora hyosciami f. sp. tabacina, Phytophthora nicotianae Breda de Haan, Heliothis virescens, Orobanche ramosa L., Virus del mosaico del tabaco y Virus del grabado del tabaco (Espino, 1999). 
Tabla 1. Organismos patógenos que afectan al cultivo del tabaco (Espino, 1999)

\begin{tabular}{|c|c|c|}
\hline & Organismo patógeno & Enfermedad \\
\hline Hongos & $\begin{array}{l}\text { Peronospora hyoscyami f. sp. tabacina } \\
\text { Phytophthora parasitica var. nicotianae Breda de Haan } \\
\text { Rhizoctonia solani Kuhn } \\
\text { Fusarium oxysporum var. nicotianae } \\
\text { Cercospora nicotianae Ell. y Ev. } \\
\text { Alternaria tenuis Nees. } \\
\text { Pythium sp. } \\
\text { Collectotrichum destructivun O'Gara }\end{array}$ & $\begin{array}{l}\text { Moho Azul } \\
\text { Pata Prieta } \\
\text { Damping-off* } \\
\text { Marchitamiento } \\
\text { Ojo de rana } \\
\text { Alternaria } \\
\text { Damping-off * } \\
\text { Antragnosis * }\end{array}$ \\
\hline Virus & $\begin{array}{l}\text { Virus del mosaico del tabaco (VMT) } \\
\text { Virus del grabado del tabaco (VGT) } \\
\text { Virus "Y" de la papa (VYP) } \\
\text { Virus del encrespamiento foliar del tabaco (VEFT) } \\
\text { Virus del mosaico del pepino (VMP) }\end{array}$ & \\
\hline Bacterias & Erwinia carotovora (Jones) Holland & Tallo Hueco \\
\hline Insectos & $\begin{array}{l}\text { Heliothis virescens Fabricio } \\
\text { Manduca sexta Bult. } \\
\text { Myzus persicae Sulzer } \\
\text { Prodenia sp. } \\
\text { Trichoplusia ni } \\
\text { Heteroderes laurentii Guerin } \\
\text { Grillotalpa hexadactila Perty } \\
\text { Feltia sp. }\end{array}$ & $\begin{array}{l}\text { Cogollero del tabaco } \\
\text { Primavera del tabaco } \\
\text { Pulgón verde } \\
\text { Mantequilla } \\
\text { Falso medidor } \\
\text { Pasador del tabaco } \\
\text { Verraquito de la tierra } \\
\text { Cachazudo }\end{array}$ \\
\hline Nemátodos & Meloidogyne incognita (Kofoidy white) Chitwood & \\
\hline $\begin{array}{l}\text { Fanerógamas } \\
\text { Parásitas }\end{array}$ & Orobanche ramosa $\mathrm{L}$. & Orobanche \\
\hline
\end{tabular}

$\left(^{*}\right)$ Enfermedades que afectan los semilleros.

El Moho Azul, causado por el patógeno Peronospora hyoscyami f. sp. tabacina, es la enfermedad más importante que ataca al cultivo del tabaco en los países donde se cultiva, pudiendo destruir totalmente la planta, tanto en semillero como en plantaciones cuando las condiciones para el desarrollo del patógeno son favorables (Todd, 1981). Lo mismo ocurre con la bacteria del género Phythophtora, que además de ser de rápido accionar destructivo en el cultivo del tabaco, lo resulta en el cultivo de la papa. (Pérez y Forbes, 2008). Diferentes fito-mejoradores y productores, han coincidido en plantear que, en los últimos años, a pesar del empleo de fungicidas químicos y del manejo de variedades en las diferentes áreas sembradas, el hongo ha aumentado su incidencia y afectaciones en las plantaciones (Espino, 1999).

La sintomatología de esta enfermedad es característica, en la fase de postura se pueden ver manchas circulares amarillas en los semilleros, que corresponden con las plantas afectadas.

En las plantaciones (figura 1), se puede ver en el envés la aparición del moho gris-azuloso mientras en el haz de las hojas permanece aparentemente normal durante los primeros días, después cambia de color a carmelita en los puntos afectados, terminando con la necrosis de la hoja. Las hojas retardan el crecimiento, las raíces se afectan también (Lucas, 1975). Se ha reportado la infección sistémica (Shew y Lucas, 1991). 


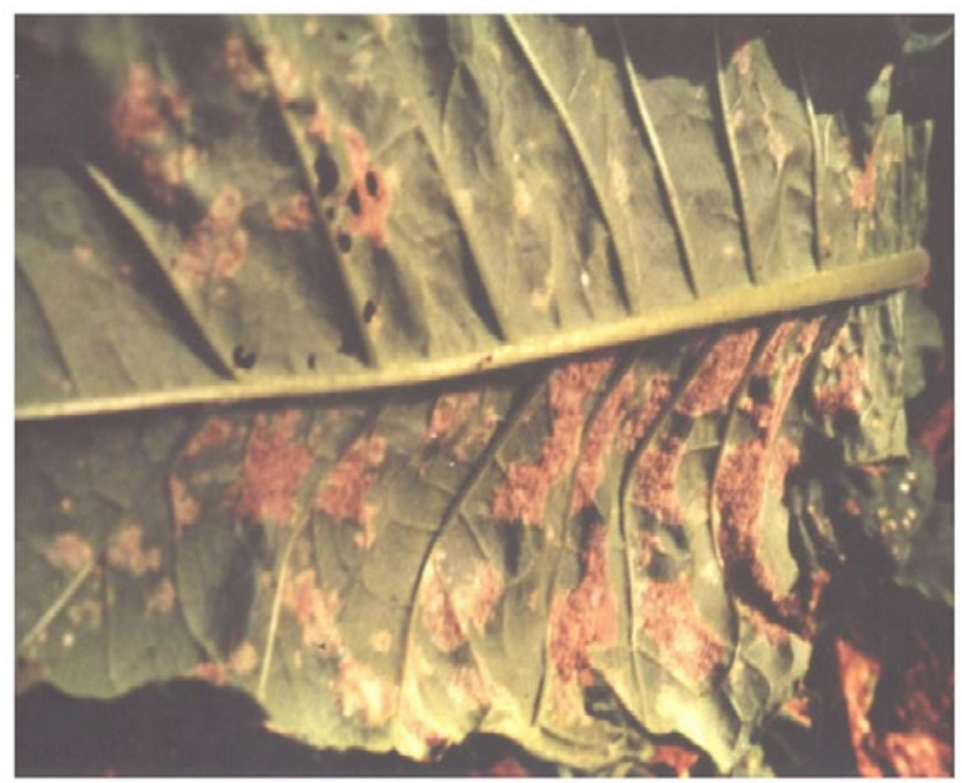

Figura 1. Sintomatología característica del Moho Azul causado por el hongo Peronospora hyoscyami en una hoja de tabaco.

En 1990 Spurr y Menetrez describieron la diversidad poblacional de Peronospora hyoscyami desde el punto de vista de su variabilidad genética. Esto tiene implicaciones epidemiológicas directas y explica por qué en ocasiones hay años sin la presencia de la enfermedad, o tener áreas geográficas locales que escapan de la enfermedad (Lucas, 1975).

\section{Mejoramiento genético Métodos tradicionales}

El género Nicotiana es considerado un remanente de un complejo poliploide que posiblemente haya evolucionado mediante la anfiploidia y la diferenciación génica provocada por aneuploidia, mutaciones espontáneas y recombinaciones genéticas (Goodspeed, 1954; Siva et al., 2008).

En Cuba el tabaco se mejora de forma integral, lo que la coloca en una posición privilegiada en cuando el conocimiento de su genética y manejo, lo que supone la obtención de nuevas variedades con las mejores características agronómicas e industriales y que además sean resistentes a los principales organismos patógenos, manteniendo los parámetros organolépticos.

Las variedades comerciales de tabaco en su mayoría presentan alta fertilidad. Esta es una ventaja para la realización de programas tradicionales de mejoramiento, estos programas incluyen básicamente la evaluación e incorporación a la producción o a los programas de cruzamiento de variedades foráneas y el cruzamiento de nuestras variedades con variedades foráneas o entre ellas, aplicando el método de selección genealógica para obtener nuevas variedades integralmente mejoradas. Con la aplicación de este programa se obtuvieron variedades como Corojo, Habana 92, Habana Vuelta Arriba y Habana 2000 que son resistentes a las principales enfermedades y además mantienen o superan la calidad 
y rendimientos de las variedades anteriores (Espino, 1999).

\section{Transgénesis}

Las características botánicas y fisiológicas de los géneros Nicotiana tabacum y Arabidopsis thaliana han permitido que sean las plantas modelos en las investigaciones de biotecnología vegetal y biología molecular aplicadas en los estudios básicos de la mejora vegetal. Es así como el primer trabajo de expresión de genes foráneos de interés económico en plantas transgénicas se realizó precisamente en tabaco y estuvo dirigido a conferirles capacidad autopesticida al introducir en su genoma y expresar el gen que codifica la 6 endotoxina del Bacillus thuringiensis var. Kurstaki cepa HD1 (Vaeck et al., 1987), estas plantas fueron desarrolladas por la compañía belga Plant Genetic Systems. Las larvas de Manduca sexta (primavera del tabaco) murieron después de comer de estas plantas. Posteriores experimentos en invernaderos y campo con plantas de tabaco, tomate, papa y algodón productoras de la $\sigma$ endotoxina del Bacillus thuringiensis (Bt) demostraron que las plantas transgénicas estaban protegidas contra un rango de plagas de Lepidópteros.

Se ha observado y así se selecciona, que cuando se realiza la transformación genética, las plantas transgénicas mantienen las características de la variedad, de acuerdo con la guía establecida por la Unión Internacional para la Protección de Nuevas Variedades de Vegetales (Menéndez et al., 1999).

Transformación de plantas mediada por Agrobacterium. Mecanismo molecular de transferencia y su regulación

El sistema más utilizado para la transfor- mación genética de plantas es el basado en el uso del Agrobacterium tumefaciens, donde un segmento de su plásmido inductor de tumores (Ti) se transfiere a la célula vegetal (Zambryski, 1992; Tinland y Hohn, 1995).

Los miembros del género Agrobacterium son bacterias gram negativas del suelo que pertenecen a la familia Rhizobiaceae (Lippincott et al., 1981, Farrand, et al., 2003). Se conocen 4 especies diferentes:

A. tumefaciens produce "agallas" formadas por células tumorales no diferenciadas en plantas de al menos 90 familias diferentes de gimnospermas y angiospermas dicotiledóneas. Algunas cepas de Agrobacterium no producen "agallas" pero inducen el crecimiento de teratomas, que son tumores constituidos por células diferenciadas anormalmente, frecuentemente con la apariencia de tallos o raíces.

A. rubi produce pequeñas agallas similares a tumores.

A. rhizogenes es el agente causante de la enfermedad conocida como "raíces en cabellera" al transferir el plásmido Ri "inductor de raíces". El ADN-T del plásmido Ri es transferido al núcleo de la planta donde tiene lugar la transformación (Tepfer y Casse-Delbart, 1987; Zambryski et al., 1989).

A. radiobacter es una especie avirulenta, que no causa la formación de tumores en plantas. Aunque las especies de Agrobacterium infectan a la mayoría de las especies de plantas dicotiledóneas, es conocido que existen diferentes niveles de susceptibilidad de acuerdo con la especie vegetal. Las bases genéticas de esta limitación dependen de determinantes genéticos que se encuentran en la planta y en la bacteria. 
Durante el proceso de infección natural, el Agrobacterium tumefaciens, transfiere e integra en el genoma de la planta al plásmido Ti (Piper et al., 1997), responsable de un tipo de crecimiento desorganizado e indiferenciado de las células donde se produjo la infección, apareciendo una enfermedad en las plantas conocida como "Agallas de Corona". Estos eventos de infección frecuentemente son localizados cerca de la unión del tallo y la raíz (Braun, 1982). El proceso de transformación natural Ileva implícita la interacción planta- A. tumefaciens, donde a partir del daño mecánico en la planta, se producen sustancias naturales, las cuales inducen los eventos moleculares en la bacteria, que finalmente permiten la transferencia del ADN-T a las células de las plantas.

El A. tumefaciens transforma genéticamente células vegetales provocando la aparición de tumores que sintetizan nutrientes que soportan el crecimiento de esta bacteria.

Los tumores inducidos por A. tumefaciens se pueden extraer de una planta y cultivar in vitro en ausencia de reguladores del crecimiento y continúan creciendo indefinidamente. Una vez iniciada la formación del tumor no es necesaria la presencia de células de Agrobacterium para que continúe la proliferación de este. Este hallazgo llevó a Braun (1982) a postular que Agrobacterium segrega un principio inductor del tumor que origina el tipo de crecimiento anormal.

El crecimiento de las células tumorales en medio de cultivo sin la presencia de hormonas contrasta con las células de plantas normales que generalmente necesitan un suplemento de auxina y/o citoquinina para mantener el crecimiento y la viabilidad en el cultivo. En la gene- ración de teratomas provocados por algunas cepas de Agrobacterium también están implicados ciertos cambios en el balance hormonal. Los teratomas, en plantas y en cultivos pueden estar constituidos predominantemente de tejido verde de tallo o de tejido radicular. Los tumores cultivados a partir de tejidos de agallas son típicamente masas blandas de células no diferenciadas. Se puede considerar que las células de los tumores se originaron por una transformación neoplásica, es decir, la conversión de células normales a células tumorales (Grierson y Covey, 1991).

Los tumores de plantas producidos por infección de Agrobacterium sintetizan una gama de derivados de aminoácidos, Ilamados opinas (Petit y Tempé, 1975). Solo las células tumorales sintetizan opinas, los tejidos de plantas normales generalmente no producen estos compuestos (Tempé y Goldmann, 1982). En un inicio, se identificaron dos grupos de opinas: la familia de las octopinas, que son derivados carboxietílicos de la arginina, y la familia de las nopalinas, que son compuestos relacionados, conocidos como derivados carboxipropílicos de la arginina.

El Agrobacterium puede catabolizar las opinas sintetizadas por las células tumorales para obtener energía. Por ejemplo, la octopina es convertida en arginina y pirúvico por enzimas de la bacteria y estos productos son asimilados en el metabolismo celular bacteriano. Ciertas cepas de Agrobacterium inducen tumores que producen una opina específica. Únicamente la cepa de Agrobacterium implicada, o una cepa relacionada, adquiere la ventaja competitiva de poder utilizar como fuente de energía los nutrientes producidos por el tumor (Braun, 1958). Las 
cepas de Agrobacterium son clasificadas dependiendo del tipo de opina que es codificada por el ADN-T (ej. octopina, nopalina, L-succinamopina o mannopina).

El concepto del principio inductor del tumor de Agrobacterium se desarrolló a partir de la observación de que las células tumorales proliferaban en ausencia del organismo causante. Inicialmente se propusieron varias teorías en un intento por explicar este fenómeno. Se postuló que el Agrobacterium segregaba un "mensajero químico" que activaba ciertos genes latentes de la planta, pero este nunca se aisló o identificó. Otras propuestas, como la inducción de la tumorogénesis por ADN vírico o bacteriano, no fueron tampoco sustentadas experimentalmente (Grierson y Covey, 1991).

Después de las observaciones realizadas a finales de los años 60 y principio de los 70 , se encontró que incubando una cepa virulenta de Agrobacterium (C58) a $36{ }^{\circ} \mathrm{C}$, la virulencia se perdía permanentemente ( $\mathrm{Ha}$ milton y Fall, 1971). Varios laboratorios en los Estados Unidos y en Europa demostraron claramente la implicación de elementos genéticos bacterianos extra-cromosómicos en la tumorogénesis. Siguiendo el comportamiento de plantas inoculadas con mezclas de cepas de A. tumefaciens virulentas y avirulentas, se observó que el carácter de virulencia era transferido a la cepa avirulenta (Kerr, 1969). El análisis del ADN bacteriano demostró que muchas cepas de Agrobacterium poseen uno o más plásmidos extra-cromosómicos gigantes (Zaenen et al., 1974). La pérdida de virulencia de la cepa C58 después del tratamiento con calor se correlacionó con la pérdida de un plásmido. Asimismo, la transferencia del plásmido de una bacteria virulenta a cepas avirulentas confería oncogenicidad a la cepa receptora.
La conclusión de estos y otros experimentos (Van Larabeke et al., 1975.; Watson et al., 1975), fue que la transformación de las células de las plantas por Agrobacterium es causada por un plásmido bacteriano.

Los genes involucrados en el catabolismo de opinas son de naturaleza procariota en cuanto a que son operones inducibles. Su transcripción es inducida en presencia de moléculas de opinas. Las células del tumor empiezan a producir opinas dirigidas por los genes opina sintetasa del ADN-T. Las opinas, que difunden fuera de las células tumorales, penetran en las células de Agrobacterium e inducen la expresión de los genes del metabolismo de opinas localizados en el plásmido Ti, y también la transferencia del plásmido Ti a otras cepas de Agrobacterium que carecen de este plásmido. De esta forma, la cepa de Agrobacterium inductora sobrevive utilizando las opinas codificadas por el plásmido Ti y fabricadas en el tumor vegetal, y la capacidad de sintetizar opinas, es diseminada entre otras bacterias por transferencia del plásmido (Grierson y Covey, 1991).

Los plásmidos Ti que codifican una opina dada, codifican también para aquellas enzimas necesarias para el catabolismo de dicha opina. Así, la cepa de A. tumefaciens que codifique los determinantes genéticos para la síntesis y catabolismo de nopalina, es clasificada como una cepa con un plásmido tipo nopalina. De forma similar fueron caracterizados los plásmidos tipo octopina, así como también de agropina y succinamopina, y de otras opinas producidas por diferentes cepas de Agrobacterium.

En la parte del plásmido Ti que no se integra al genoma de la planta, se mapearon 
varios genes importantes, relacionados con la asociación entre la bacteria y la planta. Por ejemplo, el catabolismo de opinas está controlado por loci localizados en el brazo derecho de la molécula, cerca de un locus (tra), que codifican la enzima necesaria para la transferencia conjugativa del plásmido Ti a cepas avirulentas de Agrobacterium. El brazo izquierdo del plásmido Ti contiene la región de virulencia (vir), que es activada por compuestos exudados de las células vegetales heridas (Stachel y Zambryski, 1986). Este importante segmento controla la movilización del ADN-T como una fase previa a la transformación.

En la fase inicial de interacción, el Agrobacterium, ataca las paredes celulares de las células vegetales lesionadas mecánicamente, donde se multiplica (Lippincott y Lippincott, 1969). Este proceso está controlado por dos loci de virulencia de Agrobacterium (chvA y chvB), localizados en el cromosoma bacteriano. Los genes en estos 2 loci están constantemente expresados en las células de Agrobacterium, es decir, su expresión es constitutiva (Hooykaas y Schilperoort, 1992). Los productos de los genes chv A y chv B solamente pueden promover la unión cuando Agrobacterium está en la proximidad de células vegetales dañadas, donde presumiblemente los sitios de unión llegan a estar expuestos después del daño. Estas células vegetales también excretan moléculas inductoras que activan ciertos genes en la región vir del plásmido Ti. En contraste con los genes de virulencia cromosómicos, los genes vir del plásmido Ti están estrechamente regulados.

En tabaco identificaron dos compuestos de la planta que activan específicamente los genes vir del plásmido Ti (Stachel et al., 1985). Estos son: La acetosiringona (AS), que es una sustancia lipofílica que se acumula con facilidad en la membrana bacteriana interna o pasar a través de ella y la $\alpha$ - hidroxi acetosiringona (OH-AS). Estas sustancias también activan la región vir de aislamientos de Agrobacterium crecidos en medio de cultivo. Además, ligeras modificaciones químicas de los inductores reducen dramáticamente su eficacia, demostrándose cuán altamente específica es la respuesta. En otras especies vegetales otros compuestos pueden ser los responsables de la inducción de los genes de virulencia.

Una explicación al por qué las plantas monocotiledóneas no son fácilmente infectadas por el Agrobacterium podría ser, que las células vegetales dañadas no exudan compuestos fenólicos inductores de los genes vir (Usami et al., 1987). Sin embargo, la formación de tumores es el resultado final de un complejo proceso en el cual están involucrados varios pasos, incluyendo el reconocimiento de las células vegetales por el Agrobacterium, el contacto de éste con las mismas, la transferencia del ADN-T, su expresión, integración dentro del genoma, y expresión de los síntomas por las células vegetales transformadas.

Los loci genéticos de virulencia se denominaron vir A, B, C, D, E y G. La regulación de los operones vir está mediada por la expresión constitutiva de vir A y vir G. La proteína vir A está en la membrana bacteriana interna (Leroux et al., 1987; Melchers et al., 1989) y es capaz de detectar desde su posición a los compuestos fenólicos. Esta molécula es necesaria para la transportación de las moléculas que inducen la AS a través de la membrana celular, desde la proximidad de células vegetales dañadas hasta el interior de la célula de Agrobacterium. Se cree que AS actúa cooperativamente con la proteína 
vir $G$ para inducir la expresión de vir $B, C, D$ y $E$. La expresión de estos genes es necesaria para la escisión del ADN-T del plásmido Ti y su transferencia a la célula de la planta.

Para obtener una óptima inducción de los genes vir (Alt-Moerbe et al.,1988; Melchers et al.,1989; Stachel y Zambryski, 1986), el $\mathrm{pH}$ del medio debe estar entre 5 y 6 , la temperatura cercana a $24{ }^{\circ} \mathrm{C}$ (Dillen et al., 1997), el medio de cultivo no debe tener extracto de levadura y debe presentar un alto contenido de azúcar. La presencia de elevados niveles de inositol mejora la expresión del sistema vir (Song et al., 1991). También algunos azúcares no catabolizables tienen efectos estimulatorios (Ankenbauer y Nester, 1990; Shimoda et al., 1990).

El ADN-T es transferido y expresado en las células vegetales aún antes de la integración. Después de esta, la expresión del ADN-T es mantenida en un nivel estable, dependiendo de la posición de su integración. La expresión de los oncogenes del ADN-T da lugar a la síntesis de hormonas y a la proliferación del tumor. El tumor resultante consiste en una mezcla de células vegetales normales y transformadas.

El número de copias del ADN-T en líneas vegetales transformadas es usualmente bajo, determinándose desde una a pocas copias, raramente se han encontrado hasta 12 copias. El ADN-T no se integra en posiciones específicas del genoma, si más de una copia están presentes, pueden estar localizadas en diferentes loci del genoma vegetal o en el mismo locus (Chyi et al., 1986; Ambros et al., 1986).

El fragmento específico de ADN transferido a plantas (ADN-T) está delimitado por se- cuencias de $25 \mathrm{pb}$ repetidas (Thomashow et al., 1984). Hay genes codificantes para la superproducción de auxinas (Akiyoshi et al., 1984; Thomashow et al., 1984) y citoquininas (Barry et al., 1984), las cuales dirigen la proliferación del crecimiento de la agalla. Otros genes del ADN-T codifican para enzimas como opina sintetasas, un grupo de aminoácidos conjugados, que son catabolizados por la bacteria (Bomhoff et al., 1976).

Ha sido demostrado que, con excepción de las secuencias bordes, ningún otro gen o secuencia del ADN-T es requerida para la transferencia (Nester et al., 1981; Leemans et al., 1982). La entrada de la región codificadora del ADN-T puede ser cambiada por cualquier secuencia de ADN, permitiendo la liberación de genes deseables a las células y posterior regeneración de plantas completas (Zambryski et al., 1983). Los caracteres introducidos han sido incorporados establemente dentro del genoma nuclear y los alelos se segregan cumpliendo las leyes mendelianas (Otten et al., 1981). La transferencia del ADN es facilitada por un complejo de proteínas virulentas, codificadas en el plásmido $\mathrm{Ti}$, en un segmento de $40 \mathrm{~Kb}$ y el cromosoma bacteriano (Horsch et al., 1984).

Un problema asociado con las técnicas genéticas que utilizan plásmidos $\mathrm{Ti}$ de Agrobacterium es que estas moléculas son muy grandes (aproximadamente 200 $\mathrm{Kb})$ y por tanto difíciles de manipular in vitro. Por ejemplo, son demasiado grandes para encontrar sitios únicos de corte por enzimas de restricción en las que se puedan clonar secuencias exógenas de ADN. Para resolver este problema se han desarrollado dos estrategias de clonación que facilitan la manipulación del ADN de grandes plásmidos Ti. La primera utiliza 
un vector intermediario (Caplan et al., 1983; Horsch et al., 1984). En este caso, se extrae la región ADN-T del plásmido Ti y se clona en un plásmido pequeño de $E$. coli, pBR322, que es relativamente fácil de manipular in vitro. Luego se clona el gen foráneo de interés en pBR322, en el sitio apropiado de corte por una enzima de restricción dentro del ADN-T. A continuación, se transfiere por conjugación el vector intermediario de E. coli al Agrobacterium. Dentro del Agrobacterium, el ADN-T modificado, que contiene los genes insertados, es transferido al plásmido Ti residente por recombinación homóloga. Puesto que este proceso de recombinación es raro, y el vector intermediario se degrada rápidamente, y se transforma en un "vector lanzadera" por incorporación del origen de replicación de un plásmido de amplia gama de hospederos en el vector intermediario, de forma que pueda replicarse en Agrobacterium. También pueden seleccionarse los recombinantes por la incorporación de un gen de resistencia de antibióticos en el ADN-T clonado en el vector lanzadera. Las colonias de Agrobacterium que contienen el plásmido Ti modificado se pueden utilizar para transformar plantas.

El segundo tipo de vector para la transferencia génica a plantas, basado en el plásmido $\mathrm{Ti}$, se denomina sistema binario (Bevan, 1984). En este caso, se clonan independientemente los genes de virulencia del plásmido Ti y las secuencias del ADN-T- en plásmidos más pequeños. La clonación de secuencias de ADN exógeno en la región del ADN-T es relativamente fácil cuando éste se encuentra en un plásmido pequeño. Entonces la integración del ADN-T modificado es controlada por los genes de virulencia, activos en "trans". Ambas estrategias uti- lizaron con éxito para transferir diversas construcciones de genes a células y tejidos de plantas.

En los primeros estudios, la expresión de genes foráneos estaba limitada a tejidos tumorales, debido a las dificultades de regeneración de plantas transformadas. Posteriormente se encontró que el ADN-T podía ser desarmado por deleción de los genes oncogénicos de la biosíntesis de hormonas, sin interferir con su capacidad para integrarse en los cromosomas de las plantas (Horsch et al., 1984). En combinación con un marcador de selección como la kanamicina, esta estrategia permitió obtener transformantes no oncogénicos que se regeneraban rápidamente dando plantas enteras. Además, los genes foráneos en las plantas transformadas de esta forma se heredan, expresándose en las plantas de la progenie. Los vectores desarmados son especialmente importantes para los estudios de la expresión de genes foráneos y específicos de tejidos u órganos, debido a que se pueden regenerar plantas enteras que portan el gen manipulado en cada célula.

\section{CONCLUSIONES}

El control de plagas y enfermedades en los diferentes cultivos debe ser abordado integralmente de manera que sea eficiente el uso de los productos tradicionales en el control fitosanitario sin necesidad de elevar las dosis inicialmente recomendadas, que pueden contaminar el medio ambiente de manera irreversible, aumenta el costo de la producción y aumenta la resistencia de los patógenos.

Teniendo en cuenta que el control tradicional en diferentes patógenos es cada vez, menos eficiente, se hace necesario el estudio y entendimiento de los mecanismos de acción tanto en la planta como en los patógenos, así 
como su interacción, de manera que se puedan aplicar nuevas estrategias que permitan su control.

Las técnicas biotecnológicas, así como la ingeniería genética aplicadas a la agricultura, constituyen una nueva y buena herramienta para el control de plagas, que, unido al manejo integral de los cultivos, pueden lograr altos rendimientos sin dañar el entorno ambiental.

\section{REFERENCIAS BIBLIOGRÁFICAS}

Akiyoshi, D. E., Klee, H., Amasino, R. M. Nester, E. W. y Gordon, M. P. (1984). T-DNA of Agrobacterium tumefaciens encodes an enzyme of cytokinin biosynthesis. Proc. Natl. Acad. Sci. U S A. 81(19): 5994-5998.

Alt-Moerbe, J., Neddermann, P., Von Lintig, J., Weiler, E. W. y Schröder, J. (1988). Temperature-sensitive step in $\mathrm{Ti}$ plasmid vir region induction and correlation with cytokinin secretion by Agrobacteria. Mol. Gen. Genet. 213: 1-8.

Ambros, P. F., Matzke, A. J. M. y Matzke, M. A. (1986). Localization of Agrobacterium rhizogenes T-DNA in plant choromosomes by in situ hybridization. EMBO J. 5: 2073-2077.

Ankenbauer, R. G. y Neste,r E. W. (1990). Sugar-mediated induction of Agrobacterium tumefaciens virulence genes: structural specificity and activities of monosaccharides. J. Bact. 172: 6442-6446.

Barry, G., Rogers, S., Fraley, R. y Brand, L. (1984). Identification of cloned cytokinin biosinthetic gene. Proceedings of the National Academy of Science. USA. 81: 4776-4780.

Bevan, M.W. (1984). Binary Agrobacterium vectors for plant transformation. Nucleic Acids Res. 12: 8711-8722.
Bomhoff, G., Klapwijk, P., Kester, H., Schilperoort, R., Hernalsteens, J. y Schell, J. (1976). Octopine and nopaline synthesis and breakdown genetically controlled by plasmid of Agrobacterium tumefaciens. Molecular and General Genetics 145: 177-181.

Braun, A. C. (1958). A physiological basis for autonomous growth of crown gall tumor cell. Proc. Natl. Acad. Sci. U. S. A. 44: 344-349.

Braun, A. C. (1982). A history of the crown gall problem. En: Molecular Biology of Plant Tumours, eds. G. Kahl and J. Schell, Academic Press, New York: 155-210.

Burns, J. A. (1982). The chromosomas of Nicotiana africana Merxn: a discovered species. The Journal of heredity 73: 115-118.

Caplan, A., Herrera-Estrella, L., Inze, D., Van Haute, E., Van Montagu, M., Schell, J. y Zambryski, P. (1983). Introduction of genetic material into plant cells. Science 222: 815-821.

Chyi, Y. S., Jorgensen, R. A., Goldstein, D., Tanksley, S. D. y Loaiza-Figueroa, F. (1986). Locations and stability of Agrobacterium mediated T-DNA insertions in the Lycopersicon genome. Mol. Gen. Genet. 204: 64-69.

Clarkson, J.J, Knapp, S., Garcia, V.F., Olmstead, R.G., Leitch, A.R. y Mark W. (2004). Phylogenetic relationships in Nicotiana (Solanaceae) inferred from multiple plastid DNA regions. Data Molecular phylogenetics and evolution, ISSN: 1055-7903, Vol: 33, Issue: 1, Page: 75 - 90 https://doi.org/10.1016/j. ympev.2004.05.002.

Dillen, W., De Clercq, J., Kapila, J., Zambre, M., Van Montagu, M. y Angenon, G. (1997). The effect of temperature on Agrobacterium tumefaciens-mediated gene transfer 
to plants. The Plant Journal 12(6): 14591463.

Espino, E. (1999). El mejoramiento genético del tabaco cubano. Festival del Habano. Habanos en los umbrales del 2000. $30 \mathrm{pp}$.

Farrand, S. K., Van Berkum, P. B. y Oger P. (2003). Agrobacterium is a definable genus of the family Rhizobiaceae Free https://doi. org/10.1099/ijs.0.02445-0.

Goodspeed, T. H. (1954). The Genus Nicotiana. Crónica Botánica. Estados Unidos. $100 \mathrm{pp}$.

Grierson, D. y Covey, S. N. (1991). Plant Molecular Biology (2nd ed) Blackie and Son Limited, Bishopbriggs, Glasgow.

Hamilton, R. H. y Fall, M. Z. (1971). The lost of tumour-initiating ability in Agrobacterium tumefaciens by incubation at high temperature. Experientia 27: 229-230.

Hooykaas, P. J. J. y Schilperoort, R. A. (1992). Agrobacterium and plant genetic engineering. Plant Molecular Biology. 19: 15-38.

Horsch, R. B., Fraley R. T., Rogers S. G., Sanders P. R., Lloyd A. y Hoffman N. (1984). Inheritance of functional foreign genes in plants. Science 223: 496-498.

Kerr, A. (1969). Transfer of virulence between strains of Agrobacterium. Nature 223: 1175-1176.

Leemans, J. Deblaere, R., Willmitzer, L., De Greve, H., Hernalsteens, J., Van Montagu M. y Shell J. (1982). Identification of functions of TL-DNA transcripts in octopine crow galls. EMBO J. 1: 147-152.
Leroux, B., Yanofsky, M. F., Winans, S. C., Ward, J. E., Ziegler, S. F. y Nester, E. W. (1987). Characterization of the virA locus of Agrobacterium tumefaciens: a transcriptional regulator and host range determinant. EMBO J. 6: 849-856.

Lippincott, B. B. y Lippincott, J. A. (1969). Bacterial attachment to a specific wound site as an essential stage in tumor initiation by Agrobacterium tumefaciens. J. Bacteriol. 97: 620-628.

Lippincott, J. A., Lippincott, B. B. y Starr, M. P. (1981). Agrobacterium. En: Starr M.P., Stolp H., Trüper, H. G., Balows, A., Schlegel, H. G. (eds). The prokaryotes. A handbook on habitats, isolation and identification of bacteria Springer Verlag, Berlin Heidelberg New York: 842-855.

Lucas, G. B. (1975). Diseases of tobacco. Biological Consultory Associates. Raleight, North Carolina. USA: Third ed. 621 pp.

Melchers, L. S., Regensburg-Tuïnk, T. J. G., Bourret, R. B., Sedee, N. J. A., Schilperoort, R. A. y Hooykaas, P. J. J. (1989). Membrane topology and functional analysis of the sensory protein VirA of Agrobacterium tumefaciens. EMBO J. 8: 1919-1925.

Menéndez, E., Arrieta, J., Coego, A., Pujol, M., Coll, Y., González, S. y Selman-Housein, G. (1999). Optimización de las condiciones de bombardeo para la transformación de arroz (Oriza sativa) variedad Amistad 82. Ciencias Biológicas 30: 7-11.

Nester, E. W., Garfinkel, D. J., Gelvin, S. B. y Montoya, A. L. (1981). A mutational and transcriptional analysis of a tumor inducing plasmid of Agrobacterium tumefaciens. Mo- 
lecular Biology, Pathogenicity and Ecology of Bacterial Plasmids. 6: 467-476.

OMS (2019). Informe oms sobre la epidemia mundial de tabaquismo. Ofrecer ayuda para dejar el tabaco. Switzerland.

Otten, L., De Greve, H., Hernalsteens, J., Van Montagu, M., Schielder, O., Straub, J. y Shell, J. (1981). Mendelian transmission of genes introduced into plants by the $\mathrm{Ti}$ plasmids of Agrobacterium tumefaciens. Mol Gen Genet. 183(2): 209-13.

Pérez, W. y Forbes, G. (2008). Manual Técnico. El tizón tardío de la papa.

Petit, A. y Tempé, J. (1975). The function of T-DNA in nature. En: Molecular Form and Function of the Plant Genome. ed. L. van Vloten-Doting. Plenum Press, New York, 625-636.

Piper, K., von Bodman, S. y Farrand, S. (1993). El factor de conjugación de Agrobacterium tumefaciens regula la transferencia de plásmidos Ti por autoinducción. Nature 362, 448-450. doi: 10.1038 / 362448a0.

Shew, H. D. y Lucas, G. B. (1991). Compedium of tobacco diseases. USA: The American Phytopathological Society, 68 pp.

Shimoda, N., Toyoda-Yamamoto, A., Nagamine, J., Usami, S., Katayama, M., Sakagami, Y. y Machida, Y. (1990). Control of expression of Agrobacterium vir genes by synergistic actions of phenolic signal molecules and monosaccharides. Proc. Natl. Acad. Sci. U S A. 87(17): 6684-6688.

Siva Raju, K., Sheshumadhav, M. y Murthy, T. G. K. (2008). Molecular diversity in the genus Nicotiana as revealed by randomly amplified polymorphic DNA Physiol Mol Biol
Plants 14: 377. https://doi.org/10.1007/ s12298-008-0037-8.

Song, Y- N., Shibuya, M., Ebrizuka ,Y. y Sankawa, U. (1991). Synergistic action of phenolic signal compounds and carbohydrates in the induction of virulence gene expression in Agrobacterium tumefaciens. Chem. Pharm. Bull 39: 2613-2616.

Stachel, S. E. y Zambrysk, P.C. (1986). virA and virG control the plant-induced activation of the T-DNA transfer process of Agrobacterium tumefaciens. Cell 46: 325-333.

Stachel, S. E., Messens, E., Van Montagu, M. y Zambryski P. (1985). Identification of the signal molecules produced by wounded plant cells that activate T-DNA transfer in Agrobacterium tumefaciens. Nature 318: 624-629.

Tempé, J. y Goldmann, A. (1982). Occurrence and biosynthesis of opines. En: Kahl G., Schell J (eds). Molecular biology of plant tumors, Academic Press, New York. 427-449 pp.

Tepfer, M. y Casse-Delbart, F. (1987). Agrobacterium rhizogenes as a vector for transforming higher plants. Microbiol. Sci. 4: 2428.

Thommashow, M., Panagopoulos C., Gordon M. y Nester E. (1984). Host range of Agrobacterium tumefaciens is determined by the Ti plasmid. Nature 283. 794-796.

Tinland, B. y Hohn, B. (1995). Recombination between prokaryotic and eukaryotic DNA: integration of Agrobacterium tumefaciens T-DNA into the plant genome. En: Setlow J.K. (ed). Genetic Engineering. Vol 17: 209-229 pp. Plenum Press, New York. 
Todd, A. F. (1981). Flue cured tobacco. Producing a healthy crop. Pakin graphics. 350 pp.

Usami, S., Morikawa S., Takebe I. y Machida Y. (1987). Absence in monocotyledenous plants of the diffusible plant factors inducing T-DNA circularization and vir gene expression in Agrobacterium. Mol. Gen. Genet. 209: 221-226.

Vaeck, M., Reynaerts, A., Höfte, H., Jansens, S., De Beuckeleer, M., Dean, C., Zabeau, M., Van Montagu, M. y Leemans, J. (1987). Insect resistance in transgenic plants expressing modified Bacillus thuringiensis toxin genes. Nature (London) 328: 3337.

Van Larabeke, N., Gentello, C., Schell, J., Schilperoort, R. A., Hermans, A. K., Hernalsteens, J. P. y Van Montagu, M. (1975). Acquisition of tumour-inducing ability by non-oncogenic agrobacteria as a result of plasmid transfer. Nature 255: 742-743.

Vavilov, I. (1936) Studies on the origin of cultivated plants. Inst. Appl. Biol. Pf. Bound. Watson, B., Currier, T. C., Gordon, M. D. Chilton, M. D. y Nester, E. W. (1975). Plasmid required for virulence of Agrobacterium tumefaciens. J. Bacteriol. 123: 255-264.

Zaenen, I., Van Larebeke, N., Teuchy, H., Van Montagu, M. y Schell, J. (1974). Supercoiled circular DNA in crown gall inducing Agrobacterium strains. J. Mol. Biol. 86: 109127.

Zambryski, P., Joos, H., Genetello, C., Leemans, J., Van Montagu, M. y Schell, J. (1983). Ti plasmid vector for the introduction of DNA into plant cells without alteration of their normal regeneration capacity. EMBO J. 2: 21432150.
Zambryski, P., Tempé, J. y Schell, J. (1989). Transfer and functions of T-DNA genes from Agrobacterium Ti plasmids in plants. Cell 56: 193-201.

Zambryski, P. C. (1992). Chronicles from the Agrobacterium plant cell DNA transfer story. Anu. Rev. Plant Mol. Biol. 43: 465-490. 